\title{
Contrastive Linguistics and Translation Studies Interconnected: The Corpus-based Approach
}

\author{
Noelia Ramón García \\ University of León (Spain)
}

The relationship between contrastive linguistics $(C L)$ and translation studies (TS) as two disciplines within the field of applied linguistics has been explored in depth by several authors, especially in the 1970s and early 1980s. From the mid-nineties on both these disciplines have experienced a great boom due to the use of computerised language corpora in linguistic analysis. We will argue in this paper that this new corpus-based approach to CL and TS makes it necessary to revise the relationship between them, and look for a new common ground to work on. Our hypothesis is that the use of translation equivalence as a tertium comparationis for a corpus-based contrastive analysis provides essential data for TS in a wide range of aspects. On the other hand, the corpus approach of TS has shed a new light on numerous aspects of $C L$.

\section{Introduction}

The introduction of electronic language corpora has resulted in major changes in the world of linguistic research in general. From the late 1980s and early 1990s on, the developments in computing, text scanning, information storage and text processing have been enormous and linguists soon realised these new tools offered great possibilities for language description and analysis. Today language corpora may easily include millions of words from real texts stored in machine-readable form, and the number of sophisticated analytical tools that can be applied to those texts is increasing fast. Corpora contain huge amounts of authentic samples of the language and are undoubtedly an invaluable tool for studying language in use. The importance of corpora lies in the fact that they reveal patterns of language usage which would not be easily detected otherwise, since "the language looks rather different if we look at a lot of it at once" (Sinclair 1991:100).

Linguistic disciplines that focus on the relationship between two or more languages have also experienced great progress thanks to the use of computer corpora. This paper will deal with two of these disciplines, contrastive linguistics (CL) and translation studies (TS), and the changes they have undergone since the use of corpora has become common in the field. We will argue here that the new perspective provided by the corpus-based approach has not only led to important developments in these two disciplines, but that corpora have also contributed to a new type of relationship between CL and TS. This new relationship builds on previous approaches, but reveals innovative trends within both academic disciplines. One of the ideas put forward in this paper relates to a new separate branch of CL devel- 
oped in recent years and showing a closer link with translation than standard $\mathrm{CL}$ as we knew it before the expansion of language corpora. Another interesting feature refers to the use of contrastive methods in corpus-based TS, showing to what extent CL and TS are interrelated.

\section{What are CL and TS? A brief review}

\subsection{Contrastive Linguistics}

CL started developing in the 1940s and 1950s (Fries 1945; Lado 1957) as an independent discipline within the field of applied linguistics to fulfil new needs arising in foreign language teaching. Various other terms are also currently used to refer to this same discipline, such as contrastive analysis, contrastive studies or cross-linguistic studies. Although there are subtle differences between these terms, for the purpose of this paper we may consider them as synonyms. We can define CL as "the systematic synchronic study of similarities and differences in the structure and use of two or more language varieties, carried out for theoretical or practical purposes." (Bugarski 1991:77).

Some of the most relevant features related to this discipline are listed below:

- The systematic comparison of two or more languages can be carried out at different levels, from phonetics, to grammar, lexis or text linguistics. Microlinguistic studies were the focus in the first years, but contrastive studies have also been carried out at higher levels.

- A contrastive study can be said to consist of three steps: "description, juxtaposition and comparison.” (Krzeszowski 1990:35). First, the particular phenomenon that is to be contrasted has to be described in the languages involved. The resulting descriptions have to be juxtaposed to observe similarities and differences. And finally, the differences found are to be contrasted in order to determine the possible cross-language correspondences. CL focuses primarily on differences between languages.

- The linguistic description of the two languages can be carried out according to any linguistic model, but the same model should be applied in both cases. The approaches that deal with CL include generative models (Krzeszowski 1990) and functional models (Chesterman 1998), among others.

- The concept of tertium comparationis is central to CL, since it refers to the criterion used for the actual comparison. A great number of authors have tried to name the common ground shared by two languages that could be used as a starting point for a contrastive analysis. The most commonly used criterion is equivalence, particularly translation equivalence (Halliday et al. 1964; 
James 1980; Ivir 1981). This fact is of great significance in studying the relationship between CL and TS. Most contrastive linguists have either explicitly or implicitly made use of translation as a means of establishing cross-linguistic relationships, and James has stated that "translation equivalence, of this rather rigorously defined sort [including interpersonal and textual as well as ideational meaning] is the best available TC [tertium comparationis] for CA [contrastive analysis]." (James 1980:178)

CL attained an immediate success in the first decades of its existence and great expectations were set on this new area to improve students' learning processes. By the late 1970s though, it had become obvious that the results obtained were unreliable and did not differ much from what a foreign language teacher could have foreseen on the basis of his daily practice. The interest in CL declined greatly and was only rekindled in the 1990s when new electronic tools, especially computer corpora, brought a much-needed boost to the discipline. The availability of huge amounts of machine-readable texts led to a shift in the focus of CL from linguistic systems in a more abstract sense to more specific issues in language use; from a static linguistic description, to a more dynamic approach. Together with this new perspective, the traditional application of CL to foreign language teaching gradually gave way to an increasing interest in the possible applications for translation. This interest of CL in translation phenomena is parallel to the development of this field of knowledge into a fully-fledged academic discipline.

\subsection{Translation Studies}

TS as an independent discipline with its own object of study, aims and methods cannot be said to have been fully established before the 1970s and 1980s (Bassnett 1980), and some still consider it to be largely a field of study rather than a proper scientific discipline. From the mid-1950s there had been a growing interest in analysing the process of translation from different perspectives, particularly linguistic ones, but no clear-cut approach had yet been put forward to integrate all the different aspects that play a role in the translation process. Thus, translation was regarded as a subdivision of other disciplines such as CL or interlanguage studies.

The theory and method for comparing the working of different languages is known either as 'comparative descriptive linguistics' or as 'contrastive linguistics'. Since translation can be regarded as a special case of this kind of comparison, comparative descriptive linguistics includes the theory of translation. (Halliday et al. 1964:112).

This dependency of translation on other disciplines made some authors state that translation could actually be identified with a type of synchronic CL: "Im Grunde ist die Übersetzungswissenschaft nichts anderes als eine Art von 
angewandter, synchronisch-vergleichender Sprachwissenschaft unter onomasiologischem Gesichtspunkt." (Albrecht 1973:71).

Great efforts were made to free the study of translation from the bonds of other language-related disciplines. The complexity of the translation process began to be recognised and it was no longer relegated to subparts within other fields such as linguistics, literary theory or cultural studies. Translation began to be regarded as a communicative event equal to any other communicative event written originally in one particular language. The features that make translations different from original texts were the ones that had to be explored by translation scholars. Therefore, it soon became clear that what was needed was an independent academic discipline dealing with translation as its main object of study. This is what came to be named TS.

From the 1970s and 1980s TS begins to draw on models and methods from various relevant disciplines other than linguistics, such as psychology, sociology, history, and cultural studies. These models are adapted for the specific needs of TS and develop into a multidisciplinary approach to the field. One of the main innovations is the smaller importance given to heuristic problems, especially to equivalence as a static concept. Instead, scholars begin to focus on real translations, the actual products resulting from the translation process. Thus, the interest shifts from the source text (ST), previously considered to be the first-class text, to the target text (TT), which was merely regarded as a subproduct derived from the original. This focus on the TT brings with it an increased importance of language usage in translations. Corpora become an essential tool in TS, since they can provide substantial amounts of real data. Together with the importance of TTs comes the importance of the whole target system. New theories study the role of translations in the target-language polysystems (Even-Zohar 1979). The availability of huge language corpora including translated texts allows for a detailed description of the target-language environment, and according to Toury (1995) TS would only become an autonomous discipline if it managed to develop this descriptive branch, known today as Descriptive Translation Studies (DTS). The use of corpora has therefore been decisive in the development of TS into a well-established academic discipline.

\subsection{Relationship between CL and TS before the corpus-based approach}

Before corpora became widely available the relationship between CL and the discipline of translation was dominated by the lack of academic status of the latter. Both disciplines are related to language and linguistics in general, and to applied linguistics in particular. Both deal with two languages at the same time, and are therefore closely linked to the point of having been considered one and the same thing. This similarity in their objects of study makes it difficult to draw clear boundaries between CL and translation, since they share many features and actually overlap in numerous relevant aspects. The related interests of CL and translation have led to an important amount of liter- 
ature on the relationship between the two disciplines from a very early stage (Bausch 1972; Raabe 1972; Kühlwein et al. 1981), before computer corpora became widely available in language research. The early perspectives of this relationship focus primarily on two issues:

1. the usefulness of translation equivalence as the only valid tertium comparationis for a successful contrastive analysis;

2. the application of the results of a contrastive analysis in different aspects of translation studies.

In Ivir's words: "Translation can serve as a tool of contrastive analysis, while the findings of contrastive analysis may - in addition to their other practical applications - be applied in the training of translators, preparation of translation manuals, and, most importantly perhaps, in constructing a theory of translation." (Ivir 1981:209). However, at this point the application of the results of CL on translation was only starting, and the task would have been impossible to carry out without the help of computer corpora. Keeping in mind this early approach to the relationship between CL and TS, this paper will focus on the relationship from the new corpus-based perspective. We will argue that this new approach has opened the ground for closer contact and overlapping of the two disciplines. New possibilities are being explored in this relationship thanks to the wide-spread use of corpora in both fields.

\section{Why are corpora important in language research?}

The development of electronic corpora has dramatically changed the working procedures in major areas of language-related studies in the past two decades or so. The term corpus linguistics is commonly used to refer to any type of corpus-based study of the language. The amount of running text that may be compiled and stored is huge. The tools available for the search and analysis of those texts have also experienced great improvements and allow now for precise analyses of specific linguistic phenomena over large amounts of text, something that simply wouldn't have been possible before or would have taken several lifetimes to do. Broadly speaking, a corpus is "a collection of pieces of language that are selected and ordered according to explicit linguistic criteria in order to be used as a sample of the language." (Sinclair 1995:17). The most common type of corpus is a monolingual general-language corpus, which includes big amounts of real texts coming from a great variety of sources and produced spontaneously, in oral or written form, by native speakers of one particular language. If we have such a corpus stored in machine-readable form this means that we can apply a great many computerised tools to it in order to extract information: search of lexical units, syntactic structures, frequency of use, etc. It is also becoming increasingly easy to access text corpora on line and the compilation of new corpora is not as complex a process as it used to be several years ago. The importance of using a corpus in language description resides in its enabling 
"grammarians, lexicographers, and other interested parties to provide better descriptions of a language embodying a view of it which is beyond any one individual's experience." (Aston \& Burnard 1998:5). Corpora have made the old armchair linguist old-fashioned, and the basis for any hypothesis can now be tested on large amounts of language in real use.

Corpora offer a wide range of possibilities for linguistic analysis, and as computerised tools improve, new and more complex types of corpora can be designed for different purposes. This now enables researchers to compile and structure corpora in the most appropriate way to provide the information required, carefully selecting the texts to be included. It is not anymore a matter of "gathering a sufficient quantity of information, but rather selecting the data that are relevant to the linguistic mechanism one wishes to focus on."(Maniez 2002:293). However, the advantages of the use of corpora for language description should not make us forget that these electronic tools have limitations. For the most part, the search input for a corpus must take the form of single linguistic units or strings of such units. Word-class tagging, syntactic, or even semantic tagging are still far from being widely available, let alone correctly done in most corpora, since these tasks require an enormous amount of manual work that cannot be carried out by machines as yet.

The corpus typology is very complex and there is no standardised terminology to refer to the different types of corpora available. The texts included in a corpus may be in just one language (monolingual corpora), or in two or more different languages (multilingual corpora). If the texts are in just one language, they may have been produced by speakers of specific language varieties (geographical, social, etc.), or by language learners, for example. In the case of multilingual corpora, the complexity is even greater. A corpus may include texts in one language with their translations into one or more languages; or it may include texts written originally in two or more different languages, i.e. texts that are not translations of each other but share specific characteristics like date, topic and medium of publication that make them comparable; or the corpus may include translated texts from different source languages into one particular language. The technology currently available makes it possible to design further combinations of corpora for particular purposes in the future.

Together with descriptive linguistics, CL and TS have benefited substantially from the use of electronic corpora. In the following sections we will look more closely at the use these two disciplines have made of language corpora.

\section{Electronic corpora in $\mathrm{CL}$}

As mentioned above (cf. 2.1.), the first stage in any contrastive study involves the description of one particular linguistic phenomenon in two or more different languages. For the purpose of this study we will concentrate on CL involving just two languages. The use of corpora reveals itself as a 
great help in this task. A corpus provides a wide range of real examples of one and the same linguistic form or structure. Consequently, the contrastive linguist will have a sufficient number of relevant cases coming from different sources and in different contexts to explain the use of the forms in question in the two languages.

One of the first references to the usefulness of corpora for carrying out synchronic linguistic contrasts dates back to 1974 (Filipovic 1974). In these early stages, though, we are talking about rather small corpora stored generally in print, i.e. a certain amount of written texts on which to verify hypotheses of a contrastive analysis. For various reasons explained above (cf. 2.1.), CL lost much of its interest for scholars in the following years, but in the 1990s the proliferation of electronic corpora gave an important boost to CL: "Parallel corpora [i.e. multilingual corpora] are a valuable source of data; indeed they have been the principal reason for the revival of contrastive linguistics that has taken place in the 1990s." (Salkie 2002).

I have argued in this paper that it is not only corpora that have brought decisive changes into CL. The shift of the main interest for applying the results of CL from foreign language teaching to translation is another feature of the thorough reorganisation that has taken place in the discipline. Different types of corpora may be used for contrastive studies with different purposes (Lauridsen 1996; Johansson 1998). Considering the actual research that is being carried out today we can conclude that there are at least two clearly distinct orientations in modern corpus-based CL.

1. The descriptions of the specific linguistic forms have to be done independently for the two languages in order to avoid interference. We agree with Lauridsen (1996) in considering that the use of two monolingual corpora of original texts with similar features, one for each language, is the most straightforward approach in standard $\mathrm{CL}$, yielding results that represent the real language in use for both cases. This type of corpus-based contrastive analysis is being carried out at several Spanish universities in general language (Labrador de la Cruz 2000; Ramón García 2002) as well as in specialised languages (López Arroyo 2000). In this case, the studies may not be carried out with a specific applicability in mind, but only for the sake of comparison in order to describe in a contrastive way how two languages work in one specific area. The use of corpora for this type of CL resembles the use of corpora in descriptive linguistics. Monolingual corpora of the general language or of one specific language variety provide the most basic data necessary for carrying out a case study in what we will label pure or basic CL. The aim of this type of CL is to describe similarities and differences between languages, not to describe the translation process between them. The results obtained will be highly representative of the languages involved and may then be used in fields such as descriptive linguistics, foreign language teaching or translation with a guaranteed high degree of naturalness in the target language. 
It is this very authenticity of the data for the target language that makes this an excellent source of data for translation.

2. On the other hand, the growing interest in applying contrastive results to translation in particular has led many scholars to employ translation corpora as the source of data for contrastive studies, i.e. original texts and their corresponding translations into the other language. This is a clear example of overlapping of study objects in CL and translation, where the applicability in translation is considered on an a priori basis before actually carrying out the contrastive analysis. We will call this type of contrastive approach translation-oriented CL. It may be argued here that there is a disadvantage in proceeding this way, since one must rely on the high quality of the translations with regards to the extent to which they represent the target language in use without any interference from the source language. However, this shortcoming is only apparent, since this type of research usually draws on more complex corpus types, including translated as well as original texts in both languages, as in the case of the Norwegian-English parallel corpus (Johansson \& Hofland 1994). Contrastive results obtained from the analysis of original English texts and their Norwegian translations are implemented with data from a corpus of texts written originally in Norwegian, so as to complete a structure including the procedure of pure or basic CL. This two-stage analysis allows for a more comprehensive study of any linguistic phenomenon from the translational perspective. We cannot talk anymore of a mere comparison of two languages, but of a real attempt to explain the phenomenon of translation from a contrastive perspective of language in use. At this point there is no boundary between CL and TS at all. This type of translation-oriented analysis is both at the same time.

CL was previously concerned with linguistic systems rather than with language use. With the introduction of corpora, language use has become more easily accessible and the field of CL has consequently expanded.

In the case of pure or basic CL we are talking about a more linguistic approach to the discipline, without considering beforehand any possible applications of its results. This is CL for its own sake, as a discipline in its own right. The usefulness in translation is clear, since the authentic texts in the corpora guarantee the naturalness of the target language.

In the case of translation-oriented CL it is clear from the very beginning that the actual contrastive study will be carried out in order to obtain data for explaining the phenomenon of translation. The focus is on languages as interacting in real commissioned translations with a particular communicative purpose. When we consider CL from this perspective, it becomes obvious that CL is regarded as a tool for TS. It may be argued that one of these approaches may be more or less appropriate for a specific type of study, but we cannot ignore the fact that both types exist and may produce satisfactory results. 


\section{Electronic corpora in TS}

Electronic corpora have been used extensively in TS since the beginning of the 1990s and their importance is such that they have meant a turning point in the discipline. According to Laviosa, "the corpus-based approach is evolving, through theoretical elaboration and empirical realisation, into a coherent, composite and rich paradigm that addresses a variety of issues pertaining to theory, description, and the practice of translation." (Laviosa 1998:1). The empirical approach to language use as it actually occurs in translations has gradually become a more and more relevant issue. Computer corpora provide us with the necessary material in the form of huge amounts of machine-readable texts, be it originals or translations, that can be analysed in a variety of ways.

TS may well be regarded as the discipline that has posed the biggest challenges to corpus linguistics requiring a complex typology of corpora to be designed for specific purposes. It is generally multilingual corpora that can provide the clearest insights into TS, although monolingual corpora of specialized texts may also be useful in translator training or for extracting terminology in the target language. We will briefly comment upon some of the areas where research is being done in TS on the basis of different types of corpora. We will make use of the most commonly employed terminology for this area (Johansson \& Ebeling 1996):

- Translation corpora or parallel corpora: corpora consisting of texts in one particular source language and their corresponding translations into one particular target language. The analysis of this type of corpus is of obvious interest and will yield results that may be applied in translation practice, translator training, bilingual lexicography and machine translation, among other fields.

- Comparable corpora (multilingual corpora in M. Baker's terminology (1995)): corpora of original texts in two different languages. The texts are not translations of each other, but deal with the same topic and share features such as length, date and intended audience, that make them comparable. This type of corpus is not easy to compile or use due to the practical problems in matching the two corpora. They may be searched for issues related to bilingual lexicography, contrastive rhetoric, etc.

- Corpora of translated language (comparable corpora in M. Baker's terminology (1995)): this is a complex kind of monolingual corpus that includes texts translated into one particular language, for example English, from a variety of other languages, for example French, Spanish or German. It should be possible to compare these translated texts with texts written originally in English. The aim of the analysis here is to describe the features of translated language as opposed to the features of authentic language produced in real communicative contexts by native speakers. If similar features can be isolated in corpora of translated texts in dif- 
ferent languages, then we would be talking of translation universals, i.e. common characteristics of all translated texts, irrespective of the language (Laviosa 1996).

The reader may have noticed that in all these cases there are at least two different corpora involved, which means that some kind of contrastive study between the two is actually being carried out. This shows that TS relies to a great extent on the contrastive method (Hansen \& Teich 1999). In consequence, the relationship between CL and TS is so close in corpus-based approaches that no actual analysis of multilingual corpora may be carried out without using a contrastive procedure. CL is thus a must in the development of any type of TS research based on language corpora. In the case of corpora of translated language we must allow both subcorpora to include texts written in one and the same language, originals and translations. However, this does not rule out the possibility of a contrastive analysis, which could be termed an intralingual contrastive study.

Depending on the purpose of a particular study, the researcher may make use of one corpus type or another. The technology that is available allows for the combination of several types of corpora and for the most complex search methods to be applied to the texts. As far as the results are concerned, multilingual corpora have helped greatly in developing several areas within TS. Taking as a starting point Holmes's division of TS into three main areas (Holmes 1988 (1972)), theoretical, descriptive and applied TS, we may state that applied TS is the branch that has most directly profited from the use of corpora. This applied branch deals mainly with translator training, the development of translation tools (term banks, etc.) and translation assessment. The theoretical and the descriptive branches can also benefit from the use of corpora, but in less straightforward ways. The access to enormous amounts of original texts and their translations in electronic format is of obvious usefulness to professional translators, since a wide range of translation solutions are readily available for any particular source language unit by just hitting a key. Corpora are irreplaceable tools today for lexicographic or terminological purposes too, considering the availability of tools extracting statistics, and collocational patterns. Translators and students will also benefit from more accurate and language-in-use-oriented dictionaries. Translator trainers may make use of the data included in translation corpora for designing specific tasks, suggesting solutions or explaining problematic areas. The descriptive branch of TS requires a more detailed and complex analysis of multilingual corpora, but the results in the long run are bound to be spectacular. Not only linguistic units may be the object of study in a translation corpus, but also more abstract categories such as implicitness, cultural aspects or gender-related issues. Analysing an important number of translations of one particular type, with one particular audience in mind, and in one particular span of time may provide insights into such elusive issues as translation norms (Toury 1995). And finally, the advances made in all these areas will find a continuation in developments within the theoretical branch of TS, since they improve our general knowledge of the translation process and all 
the mechanisms that are involved in this complex phenomenon.

Another aspect that should be highlighted is the fact that TS draws on many different linguistic subdivisions (sociolinguistics, text linguistics, etc.), and all of these subdivisions have benefited from the use of corpora in descriptive language research. As a result, TS can be said to profit indirectly from all the advances made in all other related linguistic disciplines thanks to corpora. However, there is still a lot of work to be done to improve the way in which corpora can help TS to develop. Some of the problems scholars are encountering now are due to concordances being too short to spot certain features of translation, or to there being just one possible translation for one original text available at a time on the screen (Malmkjaer 1998).

\section{Corpus-based perspective on CL and TS interconnected}

The previous sections have shown that electronic corpora have played an essential role in reshaping the disciplines of CL and TS. The shift from more a theoretical interest towards a more dynamic approach in both areas was partly possible thanks to the availability of language corpora. As mentioned before, translation became the main interest for $\mathrm{CL}$ as opposed to previous works focusing primarily on foreign language teaching. On the other hand, the focus of TS on real translations intrinsically requires some type or other of cross-linguistic analysis which is facilitated by the use of corpora. This illustrates how modern corpus-based TS constantly draws on CL to achieve its goals. Corpus-based CL may well exist without considering translation as its most immediate application, whereas any type of approach to translation from a descriptive corpus-based perspective must take into account some kind of contrastive aspect. No study into translation can be done ignoring previous contrastive analyses, which constitute a basic starting point for the discipline. CL is thus a basic ingredient of TS.

Before corpora had become widely available the relationship between CL and TS was mainly focused on static concepts such as tertium comparationis or on the applicability of contrastive results to translation in general without any further specifications. The shift from this system-based approach to a language use approach in both disciplines has dramatically changed this view, and the possibilities offered by computer corpora have greatly supported the new tendency towards the study of real texts.

We can conclude that CL and TS present a parallel evolution in recent years, with a clear shift of focus from theoretical perspectives to descriptive and applied issues sustained by language corpora. A new and closer relationship between CL and TS has resulted from this general shift of focus. CL has turned from a basic interest in foreign language teaching to paying more attention to translation processes up to the point of having developed a separate branch that we have called translation-oriented $C L$. And the focus of TS on real translated texts and their originals has made it unavoidable to use analyses of a contrastive type. In a way we can say that CL and TS have 
turned to face each other directly and are more interrelated than ever, complementing each other constantly.

In this giving and taking of mutual help it may seem that TS is the part that benefits in a more direct way. One could even say that TS makes use of CL as a mere tool that serves its purposes: it feeds in information, has it processed, and then recovers the results for its own use. CL is limited to carrying out the parallel description of one particular linguistic aspect. In my opinion TS represents a more active role in the research process, while CL plays a less active role in the same process, but an essential one without which the whole system would tumble.

\section{Conclusions}

CL aims at acquiring knowledge about two languages on a descriptive basis and TS aims at acquiring knowledge about the actual translation process between two languages. Taking into account these fundamental differences in the goals of the two disciplines and the great similarities between them pointed out in this paper, we can conclude that CL acts on a more general basis, while TS takes the contrast between two languages to a much more specialised ground.

This paper has given an outline of the main contact areas between CL and TS. First, translation equivalence provides the necessary input for carrying out a contrastive analysis. This analysis is carried out by using electronic corpora, be they monolingual, parallel corpora or corpora of any other type. The results obtained from this contrastive analysis constitute valuable help for different areas within TS. On the other hand, corpus-based TS draws heavily upon contrastive methods on different linguistic levels for its own purposes. Recent theoretical perspectives (Rabadán 2002) suggest that CL could actually be regarded as the primary and most essential level in translation theory providing the genuine transition between theory and practice.

The corpus-based approach has not only led to important progress in CL and TS independently. It has also brought about a thorough restructuring in the disciplines and in their relationship, revealing new common grounds in CL and TS that still have to be explored in depth.

\section{Bibliography}

Aijmer, Karin, Altenberg, Bengt \& Mats Johansson (eds) (1996). Languages in Contrast. Papers from a Symposium on Text-based Cross-linguistic Studies. Lund: Lund University Press.

Albrecht, Jörn (1973). Linguistik und Übersetzung. Tübingen: Max Niemeyer.

Altenberg, Bengt \& Sylviane Granger (eds) (2002). Lexis in Contrast. Amsterdam/Philadelphia: John Benjamins.

Aston, Guy \& Lou Burnard (1998). The BNC Handbook. Exploring the British National Corpus with SARA. Edinburgh: Edinburgh University Press.

Baker, Mona (1993). "Corpus Linguistics and Translation Studies. Implications and 
Applications.” Francis Baker \& Elena Tognini-Bonelli (1993), 233-250.

Baker, Mona (1995). "Corpora in Translation Studies: An Overview and Some Suggestions for Future Research." Target 7(2), 223-243.

Baker, Mona, Francis, Gill \& Elena Tognini-Bonelli (eds) (1993). Text and Technology. In Honour of John Sinclair. Amsterdam/Philadelphia: John Benjamins.

Bassnett, Susan (1980). Translation Studies. London: Methuen.

Bausch, Karl Richard (1972). "Kontrastive Linguistik und Übersetzen." Linguistica Antverpiensia 6, 7-15.

Borin, Lars (ed.) (2002). Parallel corpora, parallel worlds. Selected papers from a symposium on parallel and comparable corpora at Uppsala University, Sweden, 22-23 April, 1999. Amsterdam: Rodopi.

Bugarski, Ranko (1991). "Contrastive Analysis of Terminology and the Terminology of Contrastive Analysis." Ivir \& Kalogjera (1991), 73-82.

Chesterman, Andrew (1998). Contrastive Functional Analysis. Amsterdam/Philadelphia: John Benjamins.

Even-Zohar, Itamar (1979). "Polysystem Theory." Poetics Today (Special Issue on Polysystem Studies by Itamar Even-Zohar) 11(1), 9-26.

Filipovic, Rudolf (1974). "The Use of a Corpus in Contrastive Studies." Raabe (1974), 51-66.

Fries, Charles Carpenter (1945). Teaching and Learning English as a Foreign Language. Ann Arbor: University of Michigan Press.

Fries, Udo, Tottie, Gunnel \& Peter Schneider (eds) (1994). Creating and Using English Language Corpora. Amsterdam/Philadelphia: Rodopi.

Gippert, Jost (ed.) (1999). Multilinguale Corpora: Codierung, Strukturierung, Analyse. Prague: Enigma Corporation.

Halliday, Michael A.K., McIntosh, Angus \& Peter D. Strevens (1964). The Linguistic Sciences and Language Teaching. London: Longmans.

Hansen, Silvia \& Elke Teich (1999). "Kontrastive Analyse von Übersetzungskorpora: ein funktionales Modell." Gippert (1999), 311-322.

Holmes, James S. (1972). "The Name and Nature of Translation Studies." Holmes (1988), 67-80.

Holmes, James S. (1988). Translated! Papers on Literary Translation and Translation Studies. Amsterdam: Rodopi.

Ivir, Vladimir (1981). "The Communicative Model of Translation in Relation to Contrastive Analysis.” Kühlwein, Thome \& Wills (1981), 209-218.

Ivir, Vladimir \& Damir Kalogjera (eds) (1991). Languages in Contact and Contrast. Essays in Contact Linguistics. Berlin: Mouton.

James, Carl (1980). Contrastive Analysis. London: Longman.

Johansson, Stig \& Knut Hofland (1994). "Towards an English-Norwegian Parallel Corpus." Fries, Tottie \& Schneider (1994), 25-37.

Johansson, Stig \& Jarle Ebeling (1996). "Exploring the English-Norwegian Parallel Corpus." Percy, Meyer \& Lancashire (1996), 3-15.

Johansson, Stig (1998). "On the role of corpora in cross-linguistic research." Johansson \& Oksefjell (1998), 3-24.

Johansson,Stig \& Signe Oksefjell (eds) (1998). Corpora and cross-linguistic research: Theory, method, and case studies. Amsterdam: Rodopi.

Krzeszowski, Tomasz P. (1990). Contrasting Languages. The Scope of Contrastive Linguistics. Berlin: Mouton.

Kühlwein, Wolfgang, Thome, Gisela \& Wolfram Wills (eds) (1981). Kontrastive Linguistik und Übersetzungswissenschaft. München: Wilhelm Fink Verlag.

Labrador de la Cruz, María B. (2000). Estudio contrastivo de la cuantificación inglés-español. PhD Thesis. University of León, Spain.

Lado, Robert (1957). Linguistics across Cultures: Applied Linguistics for Language 
Teachers. Ann Arbor: The University of Michigan Press.

Lauridsen, Karen M. (1996). "Text Corpora and Contrastive Studies: Which Type of Corpus for Which Type of Analysis.” Aijmer, Altenberg \& Johansson (1996), 63-71.

Laviosa, Sara (1996). The English Comparable Corpus (ECC): A Resource and a Methodology for the Empirical Study of Translation. PhD Thesis. University of Manchester.

Laviosa, Sara (1998). "The Corpus-Based Approach: A New Paradigm in Translation Studies." Meta 43(4), 1-6.

Laviosa, Sara (2002). Corpus-based Translation Studies: Theory, Findings, Applications. Amsterdam/New York: Rodopi.

López Arroyo, Belén (2000). Estudio descriptivo comparado inglés-español de la representación del conocimiento en los abstracts de las ciencias de la salud. PhD Thesis. University of Valladolid, Spain.

Malmkjaer, Kirsten (1998). "Love thy Neighbour: Will Parallel Corpora Endear Linguists to Translators." Meta 43(4), 534-541.

Maniez, François (2002). "The Use of Electronic Corpora and Lexical Frequency Data in Solving Translation Problems." Altenberg \& Granger (2002), 291-306.

Melchers, Gunnel \& Beatrice Warren (eds) (1995). Studies in Anglistics. Stockholm: Almqvist \& Wiksell International.

Nickel, Gerhard (ed.) (1972). Reader zur kontrastiven Linguistik. Frankfurt am Main: Fischer Athenäum.

Percy, Carol E., Meyer, Charles F. \& Ian Lancashire (eds) (1996). Synchronic Corpus Linguistics. Papers from the Sixteenth International Conference on English Language Research on Computerized Corpora. Amsterdam: Rodopi.

Raabe, Horst (1972). "Zum Verhältnis von kontrastiver Grammatik und Übersetzung." Nickel (1972), 59-74.

Raabe, Horst (ed.) (1974). Trends in kontrastiver Linguistik. Tübingen: Günter Narr.

Rabadán Álvarez, Rosa (2002). "Niveles de teorización en traducción: la transición entre teoría y práctica." Yuste Frías \& Álvarez Lugrís (2002), 7-24.

Ramón García, Noelia (2002). Estudio contrastivon inglés-español de la caracterización de sustantivos. PhD Thesis. University of León, Spain.

Salkie, Raphael M. (2002). "How Can Linguists Profit from Parallel Corpora?" Borin (2002), 93-109.

Sinclair, John (1991). Corpus. Concordance. Collocation. Oxford: OUP.

Sinclair, John (1995). "Corpus Typology. A Framework for Classification." Melchers \& Warren (1995), 17-33.

Toury, Gideon (1995). Descriptive Translation Studies and Beyond. Amsterdam/Philadelphia: John Benjamins.

Yuste Frías, José \& Alberto Álvarez Lugrís (eds) (2002) Estudios sobre traducción: teoría, didáctica, profesión. Vigo: University of Vigo Press. 